\title{
Chest Wall Leiomyosarcoma After Breast- Conservative Therapy for Early-Stage Breast Cancer in a Young Woman With Li-Fraumeni Syndrome
}

Eve Henry, MDa; Victor Villalobos, MD, PhDª; Lynn Million, $\mathrm{MD}^{\mathrm{b}}$; Kristin C. Jensen, $\mathrm{MD}^{\mathrm{c}, \mathrm{e}}$; Robert West, $\mathrm{MD}^{\mathrm{c}}$; Kristen Ganjoo, MDª Alexandra Lebensohn, MS ${ }^{\mathrm{d}}$; James M. Ford, MDª, ; and Melinda L. Telli, MD

\begin{abstract}
Li-Fraumeni syndrome (LFS) is one of the most penetrant forms of familial cancer susceptibility syndromes, characterized by early age at tumor onset and a wide spectrum of malignant tumors. Identifying LFS in patients with cancer is clinically imperative because they have an increased sensitivity to ionizing radiation and are more likely to develop radiation-induced secondary malignancies. This case report describes a young woman whose initial presentation of LFS was early-onset breast cancer and whose treatment of this primary malignancy with breast conservation likely resulted in a secondary malignancy arising in her radiation field. As seen in this case, most breast cancers in patients with LFS exhibit a triplepositive phenotype (estrogen receptor-positive/progesterone receptor-positive/HER2-positive). Although this patient met classic LFS criteria based on age and personal and family history of cancer, the NCCN Clinical Practice Guidelines in Oncology for Geneticl Familial High-Risk Assessment: Breast and Ovarian Cancer endorse genetic screening for TP53 mutations in a subset of patients with early-onset breast cancer, even in the absence of a suggestive family history, because of the potential for de novo TP53 mutations. (JNCCN 2012;10:939-942)
\end{abstract}

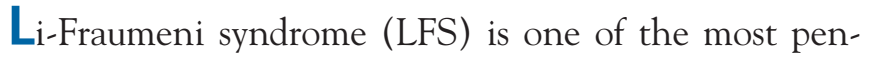
etrant forms of familial cancer susceptibility syndromes, characterized by an early age of tumor onset and a wide spectrum of malignant tumors. Patients with TP53 mutations are predisposed to develop sarcomas, early-onset breast cancer, brain tumors, leukemia, and adrenocorti-

From the Departments of a Medicine, bRadiation Oncology, cPathology, and dGenetics, Stanford University, Stanford, California, and the eDepartment of Pathology, Palo Alto Veterans Affairs Health Care System, Palo Alto, California.

Submitted April 26, 2012; accepted for publication June 14, 2012.

The authors have disclosed that they have no financial interests, arrangements, or affiliations with the manufacturers of any products discussed in this article or their competitors.

Correspondence: Eve Henry, MD, 300 Pasteur Drive, Room S-101, Stanford CA 94305. E-mail address: eve.henry@gmail.com cal carcinomas. ${ }^{1,2}$ The lifetime risk of cancer in these patients is extraordinarily high with $50 \%$ of patients having a diagnosis of cancer by the age of 30 and $90 \%$ by the age of $50 .{ }^{3}$ Identifying LFS in patients with cancer is clinically imperative because these patients have an increased sensitivity to ionizing radiation and are more likely to develop radiation-induced secondary malignancies. ${ }^{4-7}$ This case report describes a young woman whose initial presentation of LFS was early-onset breast cancer and whose subsequent treatment with breast conservation likely resulted in the rapid development of a secondary malignancy arising in her radiation field.

\section{Case Report}

A 24-year-old female presented after incidentally palpating a mass in the superior aspect of her left breast. Biopsy of the mass revealed invasive ductal carcinoma. She underwent a lumpectomy with axillary node dissection and was found to have a $2.7-\mathrm{cm}$ moderately differentiated invasive ductal carcinoma that was estrogen receptorpositive/progesterone receptor-positive/HER2-positive $(\mathrm{ER}+/ \mathrm{PR}+/ \mathrm{HER} 2+)$ on immunohistochemistry. Lymph node dissection was negative in 0 of 23 nodes. Surgical margins were negative. Imaging revealed no evidence of metastasis. She received adjuvant chemotherapy with 4 cycles of doxorubicin and cyclophosphamide, followed by 4 cycles of paclitaxel with concurrent trastuzumab. She underwent photon irradiation using an opposed tangent technique, which delivered 50.4 Gy in 28 fractions to the whole breast, followed by a 10-Gy boost to the lumpectomy cavity. She was then lost to follow-up and did not receive the intended course of adjuvant tamoxifen nor the recommended full year of trastuzumab therapy. 
Henry et al.

Twenty-seven months after completing adjuvant radiotherapy, she presented with blurry vision that rapidly progressed to right eye blindness. Brain MRI showed right globe enhancement concerning for choroidal metastasis. She had no parenchymal brain lesions. A PET/CT showed a new 4 x 3-cm left chest wall mass involving the serratus anterior muscle, extensive left breast skin thickening, bilateral pulmonary nodules, and enlarged cervical and mediastinal lymph nodes (Figure 1).

The patient received urgent radiation therapy to the right orbit to a dose of $40 \mathrm{~Gy}$ in 16 fractions and was started on tamoxifen and trastuzumab for presumed metastatic breast cancer. A CT-guided biopsy of the chest wall mass revealed a high-grade soft tissue spindle cell neoplasm consistent with leiomyosarcoma (Figure 2). Review of her prior radiation therapy fields showed the left chest wall mass to be within the prior radiotherapy field (Figure 3). Biopsy of a lung nodule, however, was consistent with metastatic breast cancer.

The patient had an extensive family history of cancer (Figure 4). Although she had previously tested negative for BRCA1 and BRCA2 germline mutations, she met the classic LFS criteria, including a diagnosis of sarcoma before age 45 years and a family history of early-onset ( $<40$ years of age) of malignancy in 2 maternal aunts and her paternal grandmother. ${ }^{8}$ After her diagnosis of leiomyosarcoma, the patient underwent genetic evaluation

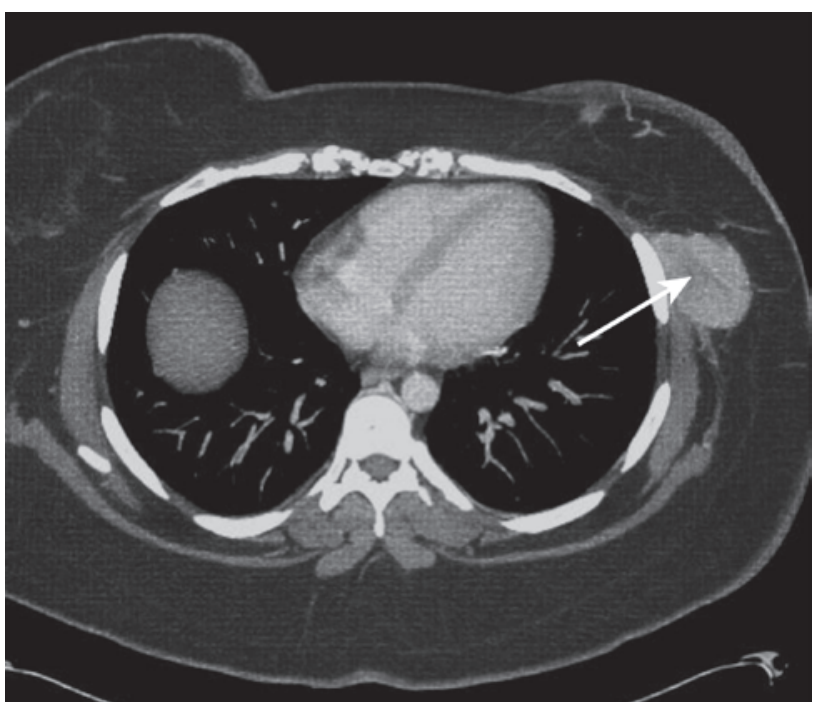

Figure 1 CT thorax with a left chest wall mass arising from the serratus anterior muscle (arrow). and tested positive for a germline mutation in TP53 (14525G $>$ T; glu286stop), confirming a molecular diagnosis of LFS.

\section{Discussion}

Although breast cancer is the most frequent neoplasm in women with TP53 mutations, it is less commonly the first presentation of LFS. The first clinical report of breast cancer as a primary presentation found 8 cases among 43 families with known LFS. ${ }^{9}$ The infrequency of LFS in the general population and the rarity of breast cancer as a primary presentation makes the diagnosis of LFS difficult in patients with early-onset breast cancer. In all patients with early-onset breast cancer, only an estimated $5 \%$ to $7 \%$ of cases can be attributed to a mutation in TP53.2,10

Despite the relative rarity of this diagnosis, this case highlights the clinical importance of considering diagnostic testing for TP53 mutations in patients with early-onset breast cancer at diagnosis. Locoregional management recommendations for these patients may be significantly influenced if LFS is detected, because the TP53 mutation confers an increased sensitivity to ionizing radiation, resulting in an increased frequency of radiation-induced secondary malignancies. ${ }^{4-7}$ Young patients are statistically more likely to choose breast conservation therapy with lumpectomy followed by adjuvant radiation therapy. ${ }^{11}$ Patients with LFS syndrome, however, are

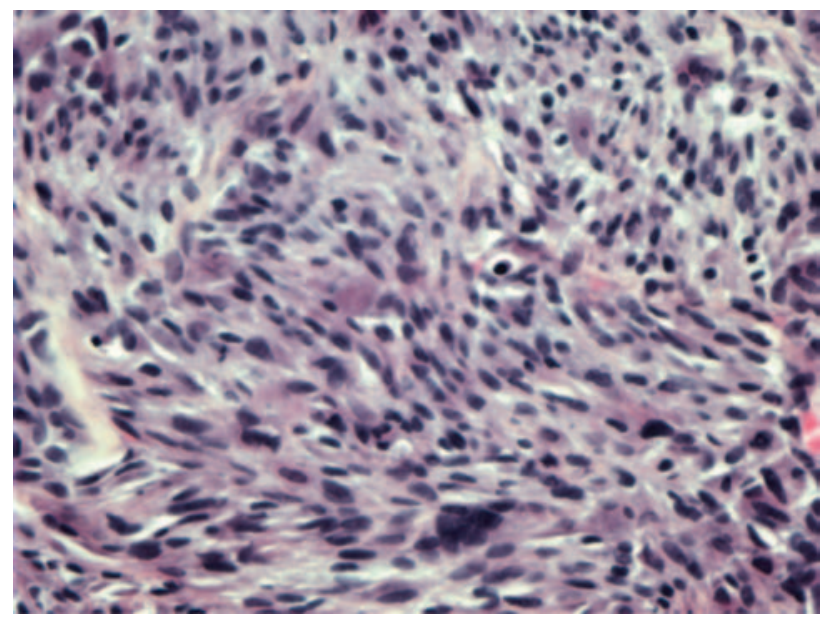

Figure 2 Spindle cell lesion with hyperchromatic, pleomorphic nuclei with increased mitotic activity. Desmin/actin positive; p63/S100/CD31/CD34 negative. Hematoxylin-eosin, original magnification $\mathrm{x} 400$. 


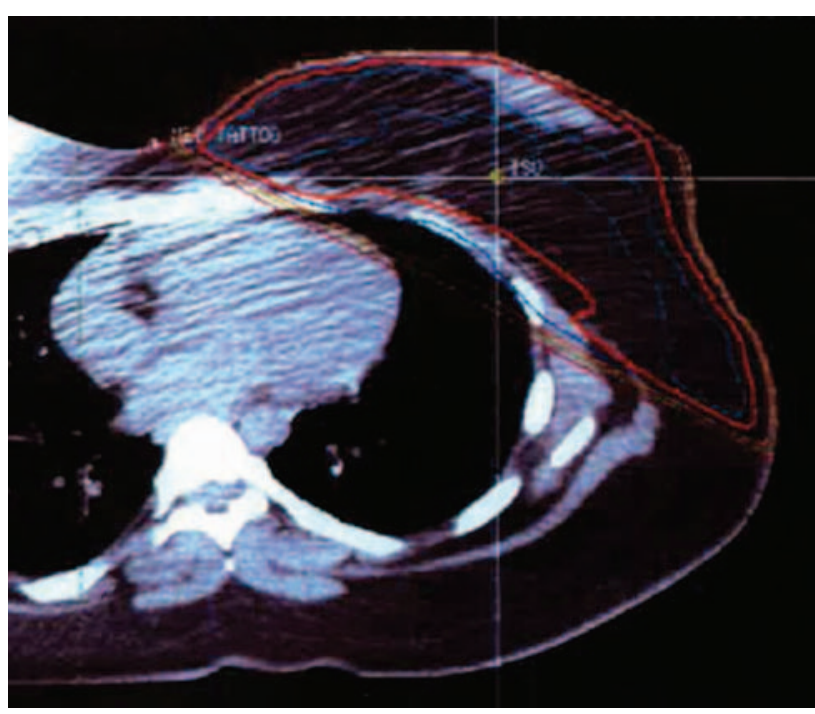

Figure 3 Isodose distribution of left breast irradiation.

cautioned to avoid radiation therapy when possible and may be advised to pursue mastectomy. ${ }^{12,13}$

In the general population, radiation-induced malignancies are rare and usually occur 10 or more years after radiation therapy. ${ }^{14}$ Even in patients with LFS, the earliest latent period to develop a second malignancy after irradiation is generally considered to be 4 years. ${ }^{15,16}$ The patient in this case developed a secondary malignancy only 2 years after the completion of whole breast radiation therapy, representing one of the shortest reported latent periods to secondary malignancy in a patient with LFS.

Because of the expense and psychosocial stress associated with genetic testing, screening all patients with early-onset breast cancer for LFS generally has not been recommended, except in those who have a compelling family history. ${ }^{17}$ Concern exists, however, that patients are being missed by this standard practice. ${ }^{18}$ In one study of women with early-onset breast cancer who tested negative for BRCA1 and BRCA2 mutations, $4 \%$ tested positive for a TP53 mutation who had no family history of cancer at all. ${ }^{10}$ Because of the possibility of de novo TP53 mutations, the NCCN Clinical Practice Guidelines in Oncology (NCCN Guidelines) for Genetic/Familial High-Risk Assessment: Breast and Ovarian Cancer

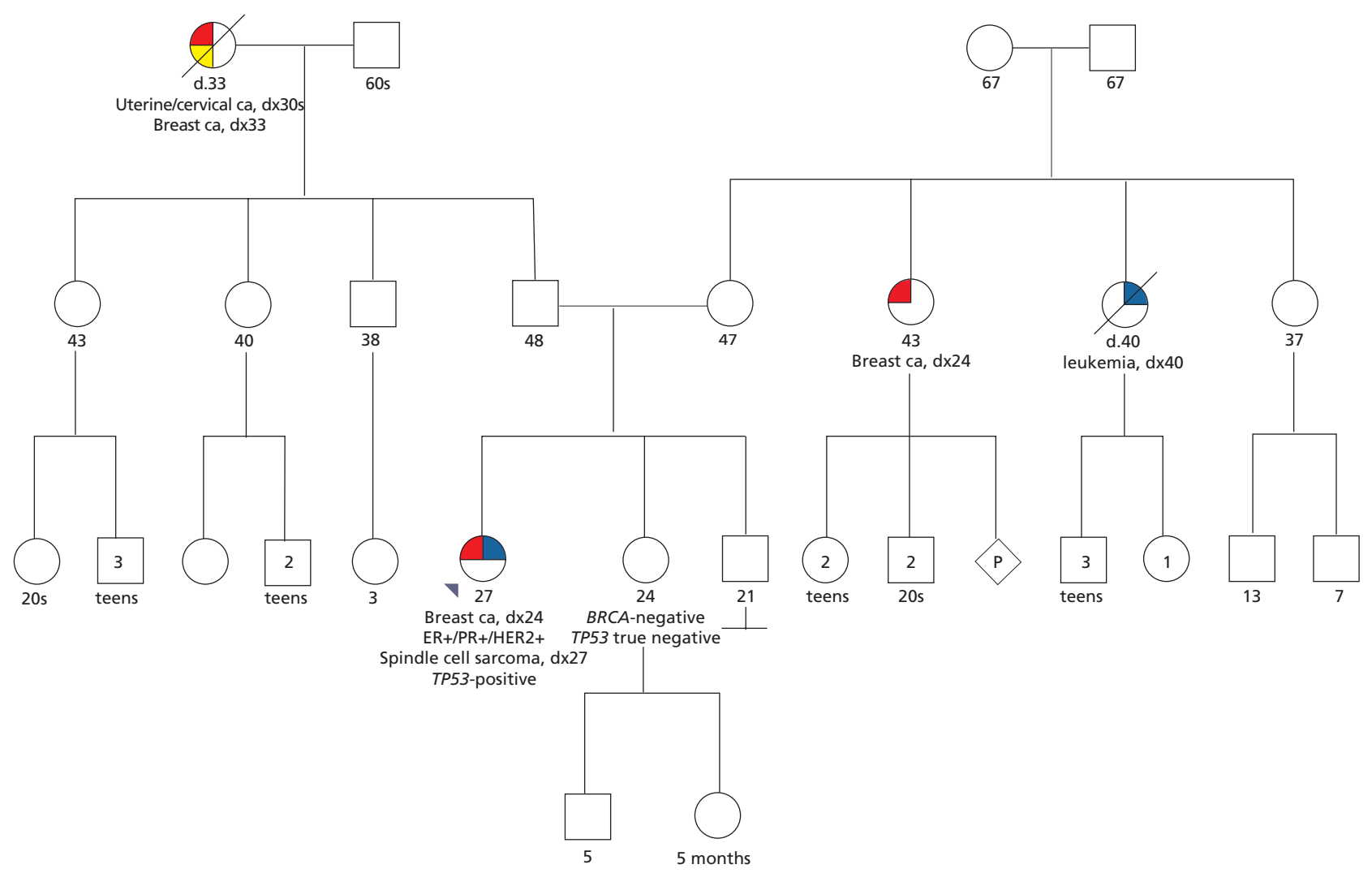

Figure 4 Pedigree.

Abbreviations: ca, cancer; $\mathrm{d}$, age at death; $\mathrm{dx}$, age at diagnosis; ER, estrogen receptor; PR, progesterone receptor. 
Henry et al.

recommend TP53 testing for individuals with multiple primary tumors, 2 of which belong to the LFS tumor spectrum (ie, sarcoma, breast cancer, adrenocortical carcinoma, brain tumor, leukemia, lung bronchoalveolar cancer) with initial cancer diagnosed at younger than 36 years regardless of family history, and in individuals diagnosed with breast cancer at younger than 30 years who have a negative BRCA1 and BRCA2 test (to view the most recent version of these NCCN Guidelines, visit NCCN.org). ${ }^{17}$ The NCCN Guidelines also recommend genetic counseling for patients who are considering p53 testing. ${ }^{17} \mathrm{~A}$ multidisciplinary approach with professional geneticists, counselors, psychologists, and oncologists may improve patient understanding of the risks and benefits associated with genetic testing. ${ }^{19}$

Research now indicates that most breast cancer in patients with LFS exhibits a "triple-positive" phenotype $(\mathrm{ER}+/ \mathrm{PR}+/ \mathrm{HER} 2+) .{ }^{20-22}$ Although family history alone may not be enough to detect all patients with LFS, a thorough family history, attention to tumor histology, and a high level of clinical suspicion may allow physicians to identify and optimize therapy for their LFS patients and minimize the potential late effects associated with this syndrome.

\section{References}

1. Olivier M, Goldgar DE, Sodha N, et al. Li-Fraumeni and related syndromes: correlation between tumor type, family structure, and TP53 genotype. Cancer Res 2003;63:6643-6650.

2. Gonzalez KD, Noltner KA, Buzin CH, et al. Beyond Li Fraumeni syndrome: clinical characteristics of families with p53 germline mutations. J Clin Oncol 2009;27:1250-1256.

3. Lustbader ED, WilliamsWR, Bondy ML, et al. Segregation analysis of cancer in families of childhood soft tissue sarcoma patients. Am J Hum Genet 1992;51:344-356.

4. Hisada M, Garber JE, Fung CY, et al. Multiple primary cancers in families with $\mathrm{Li}$-Fraumeni syndrome. J Natl Cancer Inst 1998;90:606-611.

5. Limacher JM, Frebourg T, Natarajan-Ame S, Bergerat JP. Two metachronous tumours in the radiotherapy fields of a patient with Li-Fraumeni syndrome. Int J Cancer 2001;96:238-242.

6. Cohen RJ, Curtis RE, Inskip PD, Fraumeni JF Jr. The risk of developing second cancers among survivors of childhood soft tissue sarcoma. Cancer 2005;103:2391-2396.

7. Kony SJ, de Vathaire F, Chrompret A, et al. Radiation and genetic factors in the risk of second malignant neoplasm's after a first cancer in childhood. Lancet 1997;350:91-95.

8. Li FP, Fraumeni JF Jr, Mulvihill JJ, et al. A cancer family syndrome in twenty-four kindreds. Cancer Res 1988;48:5358-5362.

9. Heymann S, Delaloge S, Rahal A, et al. Radio-induced malignancies after breast cancer post operative radiotherapy in patients with $\mathrm{Li}$ Fraumeni syndrome. Radiat Oncol 2010;5:104-109.

10. Tinat J, Bougeard G, Baert-Desurmont S, et al. 2009 version of the Chrompret criteria for Li-Fraumeni syndrome. J Clin Oncol 2009;27:108-109.

11. Greenburg CC, Lipsitz SR, Hughs ME, et al. Institutional variation in the surgical treatment of breast cancer: a study of the NCCN. Ann Surg 2011;254:339-345.

12. Limacher JM, Frebourg T, Natarajan-Ame S, Bergerat JP. Two metachronous tumors in the radiotherapy fields of a patient with Li-Fraumeni syndrome. Int J Cancer 2001;96:238-242.

13. Pierce LJ, Haffty BG. Radiotherapy in the treatment of hereditary breast cancer. Semin Radiat Oncol 2011;21:43-50.

14. Rubino C, de Vathaire F, Shamsaldin A, et al. Radiation dose, chemotherapy, hormonal treatment and risk of second cancer after breast cancer treatment. Br J Cancer 2003;895:840-846.

15. Kleinerman RA. Radiation-sensitivie gentetically susceptible pediatric sub-populations. Pediatr Radiol 2009;39(Suppl 1):S2731.

16. Schneider K, Garber J. Li-Fraumeni syndrome. In: Pagon RA, Bird TD, Dolan CR, et al, eds. Gene Reviews. Seattle, WA: University of Washington; 1999.

17. Daly MB, Axilbund JE, Buys S, et al. NCCN Clinical Practice Guidelines in Oncology: Genetic/Familial High-Risk Assessment: Breast and Ovarian. Version 1, 2012. Available at NCCN.org. Accessed June 18, 2012.

18. Gonzalez KD, Buzin CH, Noltner KA, et al, High frequency of de novo mutations in Li-Fraumeni. J Med Genet 2009;46:689-693.

19. Malkin D, Smyth $K$, Shuman $C$, et al. Establishment of a dedicated cancer genetics program in a tertiary pediatric center [abstract]. Am J Hum Genet 1999;65:Abstract 386.

20. Masciari S, Dillon D, Dick MG, et al. Breast cancer phenotype in women with TP53 germ-line mutations: an LFS consortium effort [abstract]. J Clin Oncol 2011;29(Suppl):Abstract 1519.

21. Wilson JR, Bateman AC, Hansons $\mathrm{H}$, et al. A novel Her2 positive breast cancer phenotype arising from germline TP53 mutations. J Med Genet 2010;47:771-774.

22. Melhem-Bertrandt A, Bojadzieva J, Ready KJ, et al. Early onset Her2-positive breast cancer is associated with germline TP53 mutations. Cancer 2012;118:908-913. 